\title{
Laminin enhances the growth of human neural stem cells in defined culture media

\author{
Peter E Hall ${ }^{1,2}$, Justin D Lathia ${ }^{1,2,3}$, Maeve A Caldwell ${ }^{2,4}$ and Charles ffrench- \\ Constant*1,2,5
}

\begin{abstract}
Address: ${ }^{1}$ Department of Pathology, University of Cambridge, Cambridge, UK, ${ }^{2}$ Cambridge Centre for Brain Repair, University of Cambridge, Cambridge, UK, ${ }^{3}$ Laboratory of Neurosciences, National Institute on Aging, Baltimore, USA, ${ }^{4}$ Laboratory for Integrative Neuroscience and Endocrinology, University of Bristol, Bristol, UK and ${ }^{5} \mathrm{MRC}$ Centre for Regenerative Medicine, Queen's Medical Research Institute, Edinburgh, UK Email: Peter E Hall - peter.hall@keble.ox.ac.uk; Justin D Lathia - justindlathia@gmail.com; Maeve A Caldwell - Maeve.Caldwell@bristol.ac.uk; Charles ffrench-Constant* - cffc@ed.ac.uk

* Corresponding author
\end{abstract}

Published: 23 July 2008

BMC Neuroscience 2008, 9:7| doi:|0.| |86/|47|-2202-9-7|
Received: 31 January 2008

Accepted: 23 July 2008

This article is available from: http://www.biomedcentral.com/I47I-2202/9/7I

(c) 2008 Hall et al; licensee BioMed Central Ltd.

This is an Open Access article distributed under the terms of the Creative Commons Attribution License (http://creativecommons.org/licenses/by/2.0), which permits unrestricted use, distribution, and reproduction in any medium, provided the original work is properly cited.

\begin{abstract}
Background: Human neural stem cells (hNSC) have the potential to provide novel cell-based therapies for neurodegenerative conditions such as multiple sclerosis and Parkinson's disease. In order to realise this goal, protocols need to be developed that allow for large quantities of hNSC to be cultured efficiently. As such, it is important to identify factors which enhance the growth of hNSC. In vivo, stem cells reside in distinct microenvironments or niches that are responsible for the maintenance of stem cell populations. A common feature of niches is the presence of the extracellular matrix molecule, laminin. Therefore, this study investigated the effect of exogenous laminin on hNSC growth.

Results: To measure hNSC growth, we established culture conditions using B27-supplemented medium that enable neurospheres to grow from human neural cells plated at clonal densities. Limiting dilution assays confirmed that neurospheres were derived from single cells at these densities. Laminin was found to increase hNSC numbers as measured by this neurosphere formation. The effect of laminin was to augment the proliferation/survival of the hNSC, rather than promoting the undifferentiated state. In agreement, apoptosis was reduced in dissociated neurospheres by laminin in an integrin $\beta$ I-dependent manner.
\end{abstract}

Conclusion: The addition of laminin to the culture medium enhances the growth of hNSC, and may therefore aid their large-scale production.

\section{Background}

Neural stem cells (NSC) have the ability to give rise to the three main cell types of the central nervous system (CNS), as well as being able to self-renew. As such, both public and scientific attention has focussed on them as potential therapies for neurodegenerative diseases, including multiple sclerosis and Parkinson's disease. The scarcity of pri- mary human tissue from which these NSC can be isolated has generated a need to develop protocols that allow their expansion in cell culture. As a first step towards this goal it is necessary to identify and understand the factors that regulate NSC growth and differentiation. Important clues as to the identity of these factors come from the observation that the NSC are not randomly distributed through- 
out the brain. Instead, they reside within distinct microenvironments or niches such as the ventricular/subventricular zone (VZ/SVZ) of the developing CNS and the subependymal zone (SEZ) of the adult CNS $[1,2]$. Studies of such niches from different tissues and organisms have led to the identification of common signalling molecules including growth factors, cell-cell signalling molecules, adhesion molecules and extracellular matrix (ECM) molecules, and combinations of these are therefore likely to provide strategies to maintain stem cell populations and so enhance NSC growth in cell culture $[3,4]$.

The demonstration that laminins make direct contact with adult NSC via basal lamina-like extension from blood vessels in the SVZ called fractones [5,6], and with embryonic NSC via laminins expressed within the ventricular zone [7-9], highlight the likely key role of these ECM molecules in NSC regulation. Acting mainly through the integrin family of receptors, the ECM is a key regulator of all aspects of cell behaviour, including proliferation, survival, migration and differentiation [10]. Integrins are transmembrane $\alpha \beta$ heterodimers that undergo a conformational change upon ligand binding, thereby leading to downstream effects such as actin polymerisation and synergism with growth factor signalling [10]. In other stem cell systems, the ECM has been found to inhibit the terminal differentiation of epidermal stem cells [11]. Similarly, the properties of both embryonic and spermatogonial stem cells can be maintained in vitro by growth on a laminin substrate $[12,13]$. In agreement, the elevated expression of integrins, particularly the laminin-binding $\alpha 6 \beta 1$ heterodimer, has been used to isolate stem cells from other, more differentiated cell types [14-20], and integrin $\beta 1$ has also been implicated in the maintenance of epidermal and prostate stem cells $[21,22]$. In contrast, less is known about the role of laminin/integrin interactions on human NSC (hNSC). They have been shown to promote the migration of hNSC in an integrin $\alpha 6$-dependent manner [23]; likewise a cholinergic neuronal fate is promoted by laminin [24]. However, the role of laminins in hNSC growth has not been examined. Here, we test the hypothesis that recreating features of the niche microenvironment by the addition of exogenous laminins promotes human NSC growth and provides a strategy for improving the efficiency of their propagation for translational research use.

\section{Methods}

\section{Reagents and antibodies}

$\mathrm{N} 2$ and B27 culture supplements were purchased from Gibco (Paisley, UK). Epidermal growth factor (EGF) and fibroblast growth factor-2 (FGF-2) were obtained from R\&D Systems (Abingdon, UK). Accutase was purchased from Millipore (Chandlers Ford, UK). The integrin $\beta 1$ stimulatory antibody, TS2/16, was purified from the hybridoma culture supernatant (LGC-Promochem, Teddington, UK) by incubation with Protein G beads (GE Healthcare, Little Chalfont, UK) overnight at $4{ }^{\circ} \mathrm{C}$, before being eluted according to the manufacturer's instructions. Unless already sodium azide-free, antibodies used in functional studies were dialysed overnight at $4{ }^{\circ} \mathrm{C}$ in phosphate-buffered saline (PBS) using sterile Slide-a-lyzer cassettes (Pierce, Cramlington, UK). The sterile mouse $\mathrm{IgG}_{1}$ isotype control (clone W3/25) was purchased from Serotec (Oxford, UK). Human placental laminin (hereafter referred to as "laminin") was purchased from SigmaAldrich, as were all other reagents (Poole, UK).

\section{Human cell culture}

Human fetal tissue (8-10 weeks postconception) was collected in accordance with the arrangements for informed consent recommended by the Polkinghorne Committee (1989) and the UK Department of Health guidelines (1995), and with the approval of the Addenbrooke's Hospital Medical Research Ethics Committee (Cambridge, $\mathrm{UK}$ ). The hNSC from the cortex were propagated as freefloating aggregates (neurospheres) and cellular expansion prior to use in the studies described here was achieved using a passaging method described in detail elsewhere [25]. In brief, fresh tissue was initially dissociated in trypsin and seeded at a density of 200,000 cells $/ \mathrm{ml}$ in a T75 flask containing Dulbecco's Modified Eagle's Medium (DMEM)/HAMS F12 (3:1), supplemented with N2 (1:100), EGF, FGF-2 (both at $20 \mathrm{ng} / \mathrm{ml}$ ) and heparin (5 $\mu \mathrm{g} / \mathrm{ml}$ ). Cultures were fed every $4-5$ days by replacing half the medium and spheres were passaged after 14 days expansion by cutting into $200 \mu \mathrm{m}$ sections using a McIlwain tissue chopper.

\section{Neurosphere assay}

Human neurospheres were dissociated with accutase before live cells were sorted using a MoFlo flow cytometer (DakoCytomation, Ely, UK) into 96-well plates (Nunc, Roskilde, Denmark) at a density of 500 per well $(1,500$ cells per $\mathrm{cm}^{2}$ ). In the experiments using a limiting dilution assay to determine the frequency of neurosphere-forming cells, progressively decreasing numbers of cells were plated per well. Neurosphere medium $(200 \mu \mathrm{l})$, containing EGF, FGF-2 (both at $20 \mathrm{ng} / \mathrm{ml}$ ), heparin $(5 \mu \mathrm{g} / \mathrm{ml})$ and $2 \%$ B27 together with laminin or antibodies at the concentrations indicated in the figure legends, was added per well. Prior experiments examining the effects of different laminin concentrations on mouse neurosphere numbers showed no significant increase above $10 \mu \mathrm{g} / \mathrm{ml}$ (see Additional file 1 and Additional file 2), so this concentration was used throughout for the studies on human cells. Cells were fed every 4-5 days by replacing half of the medium, and the number of neurospheres formed was counted after 21 days in culture. For the purpose of this paper, these are termed primary neurospheres. 
Secondary neurospheres were grown by collecting together primary neurospheres from a particular treatment group, dissociating them with accutase before replating at the same density using the flow cytometer in fresh medium in the absence of any antibodies or laminin. All other details are as for primary spheres.

\section{Conditioned medium}

Conditioned medium had been exposed for 5 days to neurospheres growing in a T75 flask (see 'human cell culture'), before being passed through a $0.45 \mu \mathrm{m}$ filter to remove cell debris. The percentage refers to the amount of conditioned medium added; fresh DMEM/Hams F12 constituted the remaining volume. An appropriate quantity of growth factors $(20 \mathrm{ng} / \mathrm{ml}$ EGF and FGF-2, $5 \mu \mathrm{g} / \mathrm{ml}$ heparin) and supplements ( $1 \% \mathrm{~N} 2$ or $2 \% \mathrm{~B} 27$, as indicated in the figure legends) were added according the final volume.

\section{Apoptosis analysis}

Human neurospheres were dissociated using accutase and grown for 24 hours in medium \pm laminin $(10 \mu \mathrm{g} / \mathrm{ml})$. In order to examine apoptosis, cells were incubated with fluoroscein isothiocyanate (FITC) conjugated annexin V for $15 \mathrm{~min}$ at room temperature in binding buffer (Annexin V-FITC apoptosis detection kit I, BD Pharmingen), before being analysed on at FACScan II flow cytometer (Becton Dickinson, Oxford, UK), with at least 10000 events being collected per data file. Further analysis was performed using Summit 3.0 software (DakoCytomation).

\section{Statistics}

For all neurosphere assays, 8 experimental replicates were performed for each tissue sample. The $n$ value recorded in the figure legends refers to the number of biological replicates. The data are presented as mean \pm standard error. All statistics were calculated according to the test described in the figure legends, with $p<0.05$ considered significant.

\section{Results \\ Human NSC will grow at clonal density in B27- supplemented medium}

To test our hypothesis as to the role of exogenous laminins, we needed to develop an assay that enables single dissociated cells to reveal any stem cell properties in culture. Neurospheres provide a very widely used method to grow NSC, with each neurosphere representing a 3D aggregate generated from a single NSC and containing a mixture of NSC and more differentiated cells [26]. Human NSC are commonly grown in N2 medium containing $20 \mathrm{ng} / \mathrm{ml}$ FGF2 and EGF, and are passaged by chopping the spheres into segments to be placed in fresh medium. However this approach in which large fragments are passaged does not allow accurate quantification of the effect of laminins or other manipulations on single NSC. First, therefore, we dissociated spheres passaged by chopping into single cell suspensions and re-plated them in the same medium at 1 cell/well. No neurospheres formed in these cultures (not shown). Moreover, even when higher cell plating densities of 2000, 1000 or 500 per well $(10,5$ or 2.5 per $\mu \mathrm{l}$ ) were examined, extremely low neurosphere yields were observed, with only $0.036 \pm 0.009 \%, 0.029 \pm$ $0.007 \%$ or $0.063 \pm 0.050 \%$ of the plated cells forming neurospheres, respectively (not shown).

To ask whether these dissociated human NSC had the potential to form larger numbers of spheres given more appropriate growth conditions, we attempted to mimic the much higher cell densities present in chopped spheres by the addition of conditioned medium to the culture. $50 \%$ conditioned medium added to N2/FGF2/EGF led to a 22-fold increase in the number of primary neurospheres which formed when cells were plated at 500/well (Fig. 1A; $p<0.001, n=2)$. None of the other concentrations of conditioned medium caused any significant change in neurosphere generation.

We conclude from this that the potential of the dissociated human cells to behave as NSC is much greater than as revealed by N2 medium, and that N2 does not therefore represent an appropriate choice of medium supplement for assays of human NSC behaviour and laminin effects. B27 supplement has been shown to increase the survival in culture of a range of CNS cell types, including rodent neural precursors, and is necessary to establish human neurosphere cultures from primary tissue, whereas N2 supplement is sufficient to maintain them $[25,27]$. Therefore, we next examined the effect of B27 supplement on the human neurosphere assay (Fig. 1A). When compared with N2 supplement, B27 led to a large and significant increase in primary neurosphere formation, with $3.775 \pm 0.320 \%$ versus $0.013 \pm 0.013 \%$ of cells forming primary neurospheres, respectively $(p<0.0001, n$ $=2$ ). Critically, neurosphere-conditioned medium did not increase neurosphere formation in the presence of B27, with $50 \%$ conditioned medium actually leading to a decrease in neurosphere numbers $(2.838 \pm 0.149 \%$ versus $3.775 \pm 0.320 \%$, respectively. $p<0.05, n=2)$. Consequently, these results show that B27-supplemented medium does enable human NSC to show stem cell properties in dissociated culture, and this was therefore used in all subsequent assays.

\section{Limiting dilution assays confirm that neurospheres provide a quantitative assay for human NSC}

Prior to using neurospheres as a quantitative assay of stem cell properties, it was necessary to show that the numbers of spheres formed reflected the growth of single cells and not aggregation of two or more cells after plating. To do 

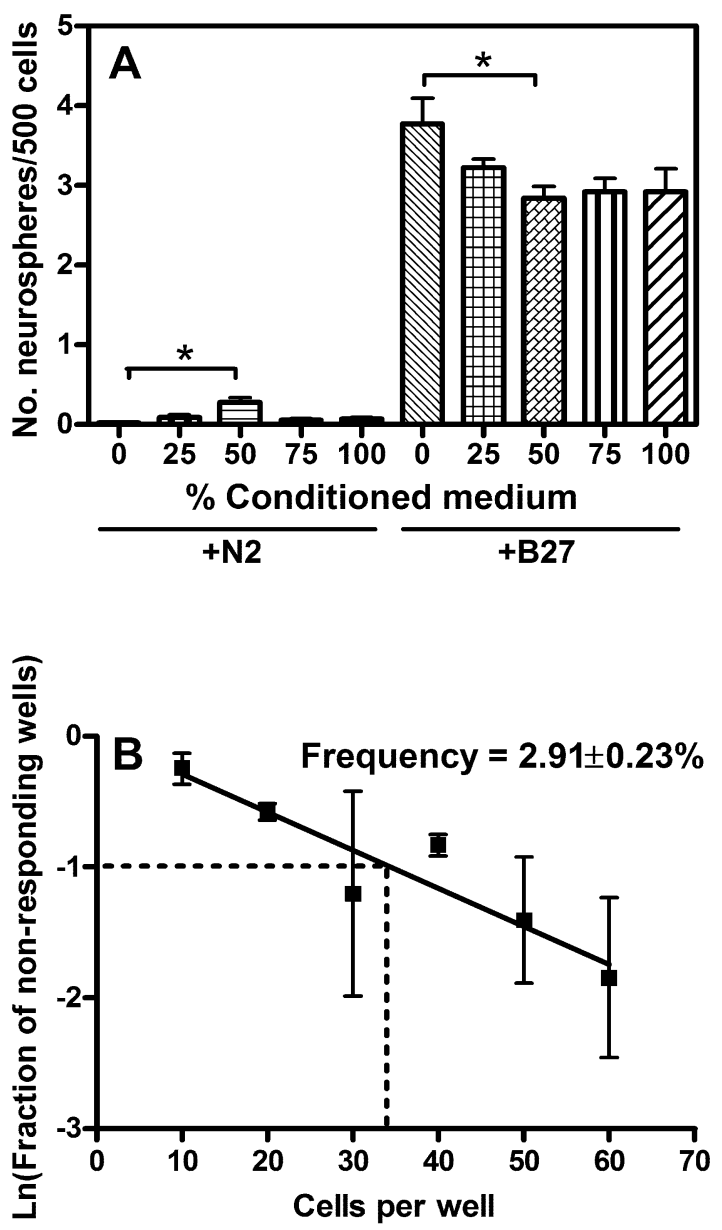

Figure I

Conditions affecting the human neurosphere assay. (A) Dissociated neurosphere cells were plated at 500 cells per well in either $1 \%$ N2 or $2 \%$ B27 supplement, together with $0-100 \%$ neurosphere-conditioned medium. Relative to no conditioned medium ( $0 \%$ ), a significant increase in neurosphere formation was observed for $50 \%$ conditioned medium only in the presence of N2 supplement. In comparison, 50\% conditioned medium significantly reduced neurosphere formation in the presence of B27 supplement. Notably, human neurosphere formation was significantly increased by $2 \%$ B27 supplement compared to I\% N2 supplement for all concentrations of conditioned medium, as determined by a one-way ANOVA with Tukey post-test $(p<0.001, n=2)$. (B) Graph showing the result of the limiting dilution assay, with cells from dissociated human neurospheres being plated at 10-60 cells per well in 2\% B27 supplement. The number of nonresponding wells (i.e. without a neurosphere present) was quantified as a fraction of the total number of wells 21 days later. Linear regression was used to produce to the line of best fit. Unless otherwise noted, statistics were determined by a one-way ANOVA with Tukey post-test. $n=2$ for all except for the limiting dilution assay, where $n=3$. $*_{p}<0.05$. this, we used a limiting dilution assay (LDA) as an alternative method to the neurosphere assay for determining the frequency of the neurosphere-initiating cell in a population. By measuring the likelihood of sphere formation in progressively greater dilutions of dissociated cells, the LDA calculates the number of individual cells able to form spheres. The neurosphere-initiating frequency determined by the LDA was $2.91 \pm 0.23 \%$ (Fig. 1B), which was not significantly different from the frequency calculated by the neurosphere assay (Fig. 1A; $3.78 \pm 0.32 \% ; \mathrm{p}=0.19, \mathrm{n}=3$ and $\mathrm{n}=2$ for the LDA and the neurosphere assay, respectively). Therefore, as the two assays gave equivalent results, neurosphere assays were used in future experiments.

\section{Laminin promotes hNSC growth}

Having established the conditions for the human neurosphere assay, the effect of soluble laminin was investigated. After 21 days in culture, two-fold more primary neurospheres had formed in the presence of laminin compared to medium alone (Fig. 2A; $p<0.05, \mathrm{n}=2$ ). When these primary neurospheres were dissociated and replated at the same clonal density but now in the absence of added laminin, no difference in the number of secondary neurospheres produced was observed (Fig. 2B; $8.63 \pm 1.00$ versus $7.00 \pm 0.82$ neurospheres per 500 cells for cells originally grown in medium or medium+laminin, respectively). Therefore, laminin increased primary neurosphere formation, but had no effect on secondary sphere growth. This shows that the relative numbers of hNSC was not increased by growth in laminin, suggesting that the effect of the laminin responsible for increased numbers of primary spheres is on NSC proliferation/survival.

\section{Augmented cell survival in the presence of laminin}

The loss of attachment to the ECM usually leads to cells undergoing anoikis [28]. Consequently, laminin in the culture medium may prevent cells from undergoing apoptosis, leading to increased primary neurosphere formation. In order to investigate this, human neurosphere cells were treated with laminin for $24 \mathrm{hrs}$ before being stained for the presence of phosphatidylserine in the external leaflet of the plasma membrane, a marker of apoptosis, by FITC-conjugated annexin V (Fig. 2C) [29]. The resulting data were normalised to the values seen with medium alone. Laminin led to a decrease in annexin $\mathrm{V}$ staining, with $73.69 \pm 4.70 \%$ of cells being annexin $\mathrm{V}^{+}$relative to medium alone $(p<0.01 ; n=5)$. As such, laminin decreased apoptosis in cells dissociated from human neurospheres.

\section{Cell survival is mediated by integrin $\beta$ I}

Integrins are the main receptor family for the ECM, with $\alpha 3 \beta 1, \alpha 6 \beta 1, \alpha 7 \beta 1$ and $\alpha 6 \beta 4$ mostly responsible for binding laminin [10]. The role of integrin subunit $\beta 1$ in medi- 

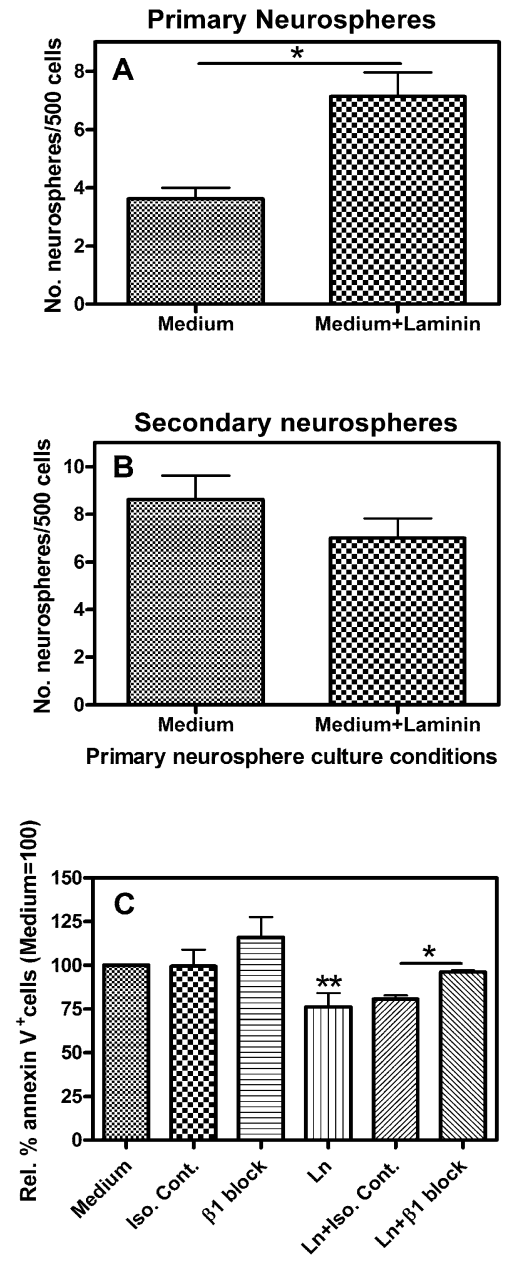

Figure 2

Laminin increases human primary neurosphere formation. (A) Cells dissociated from human neurospheres and plated in medium alone or medium containing $10 \mu \mathrm{g} / \mathrm{ml} \mathrm{lam}$ inin (Medium+Laminin). After $2 \mathrm{I}$ days, significantly more primary neurospheres had formed in the presence of laminin. (B) The neurospheres from (A) were dissociated and replated in medium alone. Note that no laminin was added to the culture medium in (B). No difference in secondary neurosphere numbers was observed. ${ }^{*} p<0.05$, as determined by Student's $t$-test; $n=2$. (C) Dissociated neurosphere cells were grown for $24 \mathrm{~h}$ in the absence (medium) or presence (Ln) of laminin, in addition to either an isotype control (Iso. Cont.) or integrin $\beta$ I-blocking antibody ( $\beta$ I block), before being analysed for annexin- $V$ expression by flow cytometry. The number of annexin- $\mathrm{V}^{+}$cells, relative to medium alone, is shown. Annexin V-binding was significantly reduced in the presence of laminin compared to medium alone, indicating an increase in cell survival. The addition of an integrin $\beta$ I-blocking antibody returned the number of annexin $\mathrm{V}^{+}$cells to control levels, indicating that laminin acts through integrin $\beta \mathrm{I}$. Statistics were determined by a one-way ANOVA with Tukey post-test. $n=5$ for medium and laminin, $n=3$ for all other conditions. ${ }^{*} * p<0.01, *_{p}<0.05$. ating the effect of laminin on cell survival was investigated further for two reasons (Fig. 2C). Firstly, integrin subunit $\beta 4$ is not expressed by human neurospheres [30]. Secondly, in parallel experiments using the much fastergrowing murine cells we found that integrin $\beta 1$-blocking antibodies negated the laminin-induced increase in neurosphere numbers (see Additional file 3 and Additional file 1). In the absence of laminin, adding an isotype control or integrin $\beta 1$-blocking antibody to the human cell cultures did not significantly alter the percentage of annexin $\mathrm{V}^{+}$cells relative to medium alone $(99.52 \pm 9.44 \%$ and $115.90 \pm 11.81 \%$, respectively). However, in the presence of laminin, the integrin $\beta 1$-blocking antibody led to a significant rise in the percentage of annexin $\mathrm{V}^{+}$cells, increasing from $80.74 \pm 2.03 \%$ in the presence of the isotype control antibody to $96.18 \pm 0.94 \%$, relative to medium alone $(p<0.05, n=3)$. Therefore, integrin $\beta 1$ is necessary for the laminin-mediated increase in survival.

\section{Integrin activation is not sufficient to recapitulate the laminin effect}

Human laminins are commonly isolated from placenta [31]. This presents three problems to its use by the biotechnology sector. First is the question of how to guarantee sufficient supply. Secondly, laminin placental preparations are heterogeneous. Depending on the purification protocol, they contain different laminins that are degraded to varying degrees, and in addition may contain fibronectin [32]. Thirdly, there may be significant variation between batches from the same manufacturer [32]. In contrast, the mouse Engelbreth-Holm-Swarm (EHS) tumour produces relatively pure and un-degraded type of laminin (laminin-111) [33]. However, in light of the expression of non-human antigens by human embryonic stem cells exposed to animal-derived culture supplements [34], it is not suitable for growing cells to be used in therapies. An alternative, more homogeneous and scaleable solution is to use a monoclonal antibody to stimulate the laminin receptor. Given the finding that laminin-dependent survival was mediated by integrin $\beta 1$, the question of sufficiency was addressed using the integrin $\beta 1$-activating antibody TS2/16 [35]. The concentration of TS2/16 used $(10 \mu \mathrm{g} / \mathrm{ml})$ was sufficient to activate integrin signalling, as demonstrated by augmented integrin $\beta 1$-dependent platelet adhesion and the increased phosphorylation of tyrosine 397 on focal adhesion kinase in human neurosphere cells (see Additional file 4 and Additional file 1) [36,37]. However, when added to the hNSC culture medium, no significant difference was observed in the number of primary (Fig. 3A) or secondary (Fig. 3B) neurospheres that formed, compared to an isotype control antibody. Therefore, $\beta 1$ integrin activation alone was not sufficient to increase neurosphere formation. 

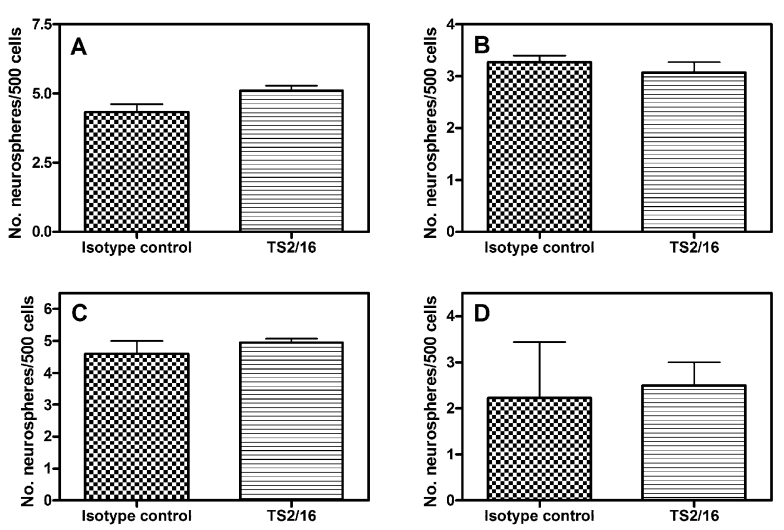

Figure 3

Activation of integrin $\beta I$ does not recapitulate the effects of laminin. (A) Cells were dissociated from human neurospheres and plated at 500 cells per well in the presence of medium supplemented with either an isotype control antibody or a $\beta$ I integrin stimulatory antibody (TS2/16; both at I0 $\mu \mathrm{g} / \mathrm{ml}$ ). Note that no alteration to the number of primary neurospheres which formed was observed. (B) Primary neurospheres were dissociated and re-plated in medium alone. Again, TS2/16 had no effect on secondary neurosphere formation. (C) As for (A), except that the cells were grown in 2 $\mathrm{ng} / \mathrm{ml}$ EGF and FGF-2, rather than $20 \mathrm{ng} / \mathrm{ml}$. (D) Secondary neurosphere formation from the primary neurospheres in (C). Statistics were determined by a one-way ANOVA with Tukey post-test. (A) $n=5$; (B) $n=4$; (C, D) $n=2$.

Growth factor and integrin signalling demonstrate considerable cross-talk [36]. For example, high levels of platelet-derived growth factor (PDGF) negate any differential effects of ECM substrates on oligodendrocyte proliferation [38]. As all cultures thus far had been supplemented with $20 \mathrm{ng} / \mathrm{ml}$ EGF and FGF-2, we examined whether a lower concentration $(2 \mathrm{ng} / \mathrm{ml})$ would allow any effects on neurosphere formation of activating integrin signalling to be observed (Fig. 3C, D). However, no significant effects of the activating antibody were found at these lower growth factor concentrations, either for the number of primary (Fig. 3C) or secondary neurospheres produced (Fig. 3D).

\section{Discussion}

The aim of this study was to investigate the role of laminins in promoting human NSC growth. Laminin was found to increase neurosphere formation and cell survival in an integrin $\beta 1$-dependent manner. However, integrin $\beta 1$ signalling alone was insufficient to recapitulate the effect of laminin.

\section{Culture medium requirements for growth of single hNSC}

The increase in human neurospheres in the presence of conditioned medium supports the observation that astrocyte-conditioned medium augments the proliferation of mouse NSC [39-41]. The presence of astrocytes within human neurospheres suggests that they could play a similar role [42]. Whilst the identity of the secreted factors in human neurosphere-conditioned medium remains to be elucidated, candidates identified from rodent studies include cystatin C, galectin-1 and pigment-derived epithelial factor (PEDF) [43,44].

We show here that the addition of B27 supplement also enables hNSC to generate neurospheres when plated at low, clonal densities. B27 supplement is chemically defined, containing the all ingredients present in N2 supplement, as well as additional factors. However, it is difficult to assess whether the effect of B27 is due to an individual factor, or the synergy of several. Interestingly, B27 also contains the antioxidant enzymes superoxide dismutase and catalase, which reduce oxidative stress and promote cell survival $[45,46]$. Although human NSC have been grown at low densities in other studies without B27 supplementation, this has been achieved by using the additional mitogen, leukaemia inhibitory factor (LIF), as well as EGF and FGF-2 [47]. LIF has been demonstrated to have a powerful positive effect on hNSC proliferation via the JAK-STAT pathway and it would be interesting to see if compounds in B27 acted through similar mechanisms [48].

\section{Laminin promotes hNSC survival}

Stem cell maintenance involves two issues: firstly, a proliferative/survival component, and, secondly, the preservation of the undifferentiated state [49]. In this study, laminin led to an increase in primary neurosphere numbers, but had no effect on secondary sphere formation. This suggests that the effect of laminin was on NSC proliferation or survival, rather than promoting the undifferentiated (stem cell) state, as the latter would be predicted to increase the number of secondary neurospheres formed form dissociated primary spheres. In agreement, laminin was found to decrease apoptosis in neurosphere cells in an integrin $\beta 1$-dependent manner. These findings support work done by Leone and colleagues, who used Cre-LoxP technology to excise integrin $\beta 1$ from neural cells in vitro [50]. They found that stem cell maintenance was unaffected by the loss of the integrin, whilst cell death was increased and proliferation was reduced. Preliminary proliferation data indicates that laminin does not alter the proportion of cells in $S$ or $\mathrm{G}_{2} / \mathrm{M}$ phase (as determined by propidium iodide incorporation and flow cytometry), whereas the addition of EGF/FGF-2 does increase this proportion. Therefore, whilst laminin-integrin $\beta 1$ interac- 
tions mediate hNSC survival, a different ECM-integrin combination appears to regulate proliferation.

At least two waves of apoptosis occur during CNS development. Cell death is prominent amongst proliferating neural stem/precursor cells and neuroblasts present in the ventricular and intermediate zones in both rodents and humans [51]. At later developmental stages, cell death mainly happens in post-mitotic neurons that have failed to innervate their targets [52]. The importance of cell death in the stem/precursor populations is shown by knock-outs of various components of the apoptotic pathway in mice. These result in the malformation of the CNS, with enlarged ventricular zones and disruption of the cytoarchitecture [53-55]. As these alterations are apparent from E9.5-E10.5, before neurogenesis commences, they must reflect a requirement for regulated cell death in the neural stem/precursor cells as part of normal development.

The function of cell death at this early stage of CNS development is uncertain, although the correction of spatial/ temporal errors, control of cell numbers or the selection for particular neuronal phenotypes have all been suggested (reviewed in $[56,57]$ ). The control of cell numbers is particularly important, as mutations that lead to the early loss of NSC during development cause microcephaly [58]. Likewise, the upstream pathways are not widely understood, although there are links with known regulators of CNS development. For example, the receptor Patched signals for cell death in neuroepithelial cells unless it is bound by its ligand, Sonic hedgehog (Shh) [59]. Similarly, signalling from receptor tyrosine kinases, via mitogen-activated protein kinase (MAPK) and Akt family members, also regulate apoptosis in the developing neuroepithelium [60-64]. This provides a potential link between the extracellular matrix and apoptosis, as integrins can activate MAPK pathways in rodent NSC [8].

\section{Laminin-mediated effects require signals additional to integrin $\beta I$ activation}

Integrin $\beta 1$ activation failed to reproduce the increased human NSC growth seen with laminin. There are three potential explanations. Firstly, integrin $\beta 1$ can form heterodimers with subunits $\alpha 1-11$, and $\alpha \mathrm{V}$, which together can bind many ECM molecules including laminins, collagens, tenascins and fibronectin [10]. The different ECM molecules have a different effect on NSC behaviour $[23,65]$. Therefore, it is possible that activating different integrin $\beta 1$ heterodimers results in opposite effects, leading to no net increase in NSC growth.

Secondly, integrin signalling is determined by both affinity regulation, through conformational changes in the subunits, and by avidity regulation, in which integrins are clustered. Laminin may form a polymer, presenting multiple integrin binding sites and thus leading to both affinity and avidity changes [28]. In contrast, it is likely that the activating $\beta 1$ integrin antibody increased affinity only and did not cause integrin clustering. As it has been shown that both processes are required for effective outside-in signal transduction [66], the activating antibody may not result in as complete a signalling response as seen with laminin even though the blocking antibody shows the integrin to be necessary for this signalling.

Thirdly, laminins have been shown to bind to a range of receptors, including dystroglycan and syndecans $[28,67]$. Dystroglycan is expressed in both the VZ and cortical plate of the embryonic brain [9]. However, mutant mice have defects in neuronal migration, consistent with the cobblestone (type II) lissencephaly phenotype seen in human congenital muscular dystrophy $[68,69]$. Therefore, it is unlikely that dystroglycan is involved in NSC regulation. However syndecans are also expressed in the VZ and cooperate with integrins in the adhesion of embryonic fibroblasts to fibronectin $[9,70,71]$. It remains to be examined whether such an interaction occurs in the response to laminin by neurosphere cells and whether syndecans and integrins together promote signalling in NSC in response to ECM.

\section{Limitations of the neurosphere assay}

The neurosphere assay we have used here represents a rapid and convenient method for assessing the number of neural stem cells within a population. However, it is not without its caveats. The main limitation is that cell types other than neural stem cells may proliferate and form spheres, based on the finding that hippocampal progenitors are able to form neurospheres which can be maintained for up to three passages $[72,73]$. Similarly, transitamplifying type $\mathrm{C}$ cells in the adult brain can also produce neurospheres $[74,75]$. Consequently, counting the number of neurospheres is not necessarily the same as counting the number of stem cells present in a population. Therefore, the absolute numbers reported in this study may be an over-calculation, with an effect of laminin on the progenitors also possibly contributing to the increased numbers of spheres seen. In order to distinguish the growth of progenitors from NSC, maintaining neurosphere cultures for at least five passages has been suggested, although the exact number of passages required remains debatable [76]. The best way to prove that any effect is directly on the stem cells would be an in vivo method such as the repopulating assay used for haematopoietic stem cells, but this has yet to be adapted for the nervous system.

The assay we have used also does not address the impact on multipotentiality of growing hNSC in laminin. The 
priming of hNSC with FGF-2/heparin/laminin prior to in vitro or in vivo differentiation resulted mainly in neurons forming, whereas the fate of unprimed hNSC was biased towards an astrocytic phenotype [77]. This is consistent with the findings of other groups that laminin induces a neuronal fate [78]. Moreover, laminin has also been implicated in altering the subtype of neuron formed. Human NSC primed as described above mostly formed cholinergic neurons, in addition to smaller numbers of glutamatergic and gamma-aminobutyric acid (GABAergic) neurons [77]. Similarly, laminin has been found to increase the ratio of GABAergic to glutamatergic neurons compared to fibronectin [79]. Therefore, it would be expected that the culture of hNSC in laminin would bias the cells towards a neuronal fate.

\section{Conclusion}

The aim of this study was to examine the role of laminin signalling in promoting human NSC growth, using an in vitro assay to isolate the cells from other niche-derived factors. Laminin was shown to increase primary neurosphere formation and the survival of human NSC. Integrin $\beta 1$ was necessary for this process, but activation of this integrin was not sufficient. Therefore, multiple receptors or receptor complexes may be necessary in order for laminin to promote hNSC growth. As it is likely that the human placental preparation used in this study contains a number of laminins including laminin-511 (LN-10, $\alpha 5 \beta 1 \gamma 1)$ [32], further work using recombinant laminins is required to define the active laminin isoform and generate reagents suitable for expanding hNSC appropriate for therapeutic use.

\section{Abbreviations}

CNS: Central nervous system; ECM: Extracellular matrix; EGF: Epidermal growth factor; FGF-2: Fibroblast growth factor-2; FITC: Fluoroscein isothiocyanate; (h)NSC: (human) Neural stem cells; LDA: Limiting dilution assay; LIF: Leukaemia inhibitory factor; SEZ: Subependymal zone; SVZ: Subventricular zone; VZ: Ventricular zone.

\section{Authors' contributions}

PEH assisted in study design, conducted the experiments, participated in data analysis and co-wrote the manuscript. JDL assisted in study design, conducted the mouse neurosphere experiments with PEH, participated in data analysis and edited the manuscript. MAC and CffC conceived and designed the study, directed PEH in his practical work and co-wrote the manuscript. All authors read and approved the final manuscript.

\section{Additional material}

\author{
Additional file 1 \\ Additional methods. \\ Click here for file \\ [http://www.biomedcentral.com/content/supplementary/1471- \\ 2202-9-71-S1.doc]
}

\section{Additional file 2}

Comparison of the effect different laminin concentrations on mouse neurosphere numbers. Mouse neurospheres were dissociated and plated at 500 cells/well in medium containing 5-20 $\mu \mathrm{g} / \mathrm{ml}$ laminin. After 7 days, the number of neurospheres formed was quantified. Compared to wells with no added laminin, significant increases were observed for all concentrations $(p<0.01)$. However, whilst $10 \mu \mathrm{g} / \mathrm{ml}$ laminin produced significantly more neurospheres than $5 \mu \mathrm{g} / \mathrm{ml}(p<0.01)$, no significant difference was found between 10 or $20 \mu \mathrm{g} / \mathrm{ml}$ laminin. Therefore, $10 \mu \mathrm{g} /$ $\mathrm{ml}$ laminin was used for all experiments on human cells. Statistics were determined by a one-way ANOVA with Tukey post-test, with 8 technical replicates performed within a single experiment.

Click here for file

[http://www.biomedcentral.com/content/supplementary/14712202-9-71-S2.eps]

\section{Additional file 3}

Laminin increases mouse neurosphere formation in an $\alpha 6 \beta 1$-dependent manner. (A) Mouse neurospheres were dissociated and plated in medium containing $10 \mu \mathrm{g} / \mathrm{ml}$ laminin ('Medium+Laminin'), resulting in augmented primary neurosphere formation after 7 days in culture. (B) However, this difference was not maintained upon passaging in medium alone (secondary neurosphere formation). (C) Graph demonstrating that the effect of laminin on primary neurosphere formation is mediated by integrin $\beta 1$. In medium alone, neither an isotype control antibody ('Iso. cont. ') nor an integrin $\beta 1$-blocking antibody (' $\beta 1$ block'; $1 \mu \mathrm{g} / \mathrm{ml}$ ) affected neurosphere formation. Significantly, though, in the presence of laminin the $\beta 1$ integrin-blocking antibody reduced neurosphere formation to control levels. (D) Similarly, an $\alpha 6$ blocking antibody (' $\alpha 6$ block'; 20 $\mu \mathrm{g} / \mathrm{ml}$ ) inhibited the effect of laminin ('Laminin') on neurosphere formation, although blocking another laminin-binding integrin, $\alpha 7$ (' $\alpha 7$ block'; $10 \mu \mathrm{g} / \mathrm{ml}$ ) did not. ITC, isotype control (A) * $\mathrm{p}<0.0001$, as determined by Student's $\mathrm{t}$-test $; \mathrm{n}=3$. $(C, D){ }^{*} \mathrm{p}<0.001$, as determined by a one-way ANOVA with Tukey post-test; $\mathrm{n}=3$.

Click here for file

[http://www.biomedcentral.com/content/supplementary/14712202-9-71-S3.eps]

\section{Additional file 4}

TS2/16 does activate integrin beta 1 signalling. (A) Platelet adhesion assay, demonstrating that the activating- $\beta 1$ integrin antibody, TS2/16, stimulates adhesion to pepsin-digested collagen I at the concentrations of $5 \mu \mathrm{g} / \mathrm{ml}$, relative to medium alone or to an isotype control antibody. (B) Western blot showing that $10 \mu \mathrm{g} / \mathrm{ml}$ TS2/16 stimulates focal adhesion kinase (FAK) phosphorylation on tyrosine 397 (pY397) after 10 min of treatment. 'Iso. Cont.', isotype control antibody $(10 \mu \mathrm{g} / \mathrm{ml}) .{ }^{*} \mathrm{p}<0.01$, relative to the isotype control or medium alone, as determined by a oneway ANOVA with Tukey post-test; $\mathrm{n}=2$.

Click here for file

[http://www.biomedcentral.com/content/supplementary/14712202-9-71-S4.eps] 


\section{Acknowledgements}

This study was supported by the Multiple Sclerosis Society (P.E.H.), the NIH-Cambridge Graduate Partnership Program (J.D.L.), the Royal Society (M.A.C.), and the Wellcome Trust (C. ff.-C.). We are grateful to Dr Nigel Miller (Wellcome Trust) for his help and advice with the flow cytometry and to Dr Pia Siljander (British Heart Foundation) for her help with the platelet adhesion assays.

\section{References}

I. Doetsch F: A niche for adult neural stem cells. Curr Opin Genet Dev 2003, 13:543-550.

2. Temple $\mathrm{S}$ : The development of neural stem cells. Nature 200I, 4| 4: 11 |2-II7.

3. Spradling A, Drummond-Barbosa D, Kai T: Stem cells find their niche. Nature 200I, 4 I4:98-I04.

4. Li L, Xie T: Stem cell niche: structure and function. Annu Rev Cell Dev Biol 2005, 21:605-63I.

5. Mercier F, Kitasako JT, Hatton GI: Anatomy of the brain neurogenic zones revisited: fractones and the fibroblast/macrophage network. J Comp Neurol 2002, 45 I : I70-I88

6. Kerever A, Schnack J, Vellinga D, Ichikawa N, Moon C, Arikawa-Hirasawa E, Efird JT, Mercier F: Novel extracellular matrix structures in the neural stem cell niche capture the neurogenic factor fibroblast growth factor 2 from the extracellular milieu. Stem Cells 2007, 25:2146-2I57.

7. Georges-Labouesse E, Mark M, Messaddeq N, Gansmuller A: Essential role of alpha 6 integrins in cortical and retinal lamination. Curr Biol 1998, 8:983-986.

8. Campos LS, Leone DP, Relvas JB, Brakebusch C, Fassler R, Suter U, ffrench-Constant C: Betal integrins activate a MAPK signalling pathway in neural stem cells that contributes to their maintenance. Development 2004, 1 3 1:3433-3444.

9. Lathia JD, Patton B, Eckley DM, Magnus T, Mughal MR, Sasaki T, Caldwell MA, Rao MS, Mattson MP, ffrench-Constant C: Patterns of laminins and integrins in the embryonic ventricular zone of the CNS. J Comp Neurol 2007, 505:630-643.

10. Hynes R: Integrins: bidirectional, allosteric signaling machines. Cell 2002, I 1 0:673-687.

II. Adams JC, Watt FM: Fibronectin inhibits the terminal differentiation of human keratinocytes. Nature 1989, 340:307-309.

12. Xu C, Inokuma MS, Denham J, Golds K, Kundu P, Gold JD, Carpenter MK: Feeder-free growth of undifferentiated human embryonic stem cells. Nat Biotechnol 200I, 19:97I-974.

13. Kanatsu-Shinohara M, Miki H, Inoue K, Ogonuki N, Toyokuni S, Ogura A, Shinohara T: Long-term culture of mouse male germline stem cells under serum-or feeder-free conditions. Biol Reprod 2005, 72:985-991.

14. Chen Z, de Paiva CS, Luo L, Kretzer FL, Pflugfelder SC, Li DQ: Characterization of putative stem cell phenotype in human limbal epithelia. Stem Cells 2004, 22:355-366.

15. Fujimoto K, Beauchamp RD, Whitehead RH: Identification and isolation of candidate human colonic clonogenic cells based on cell surface integrin expression. Gastroenterology 2002, I 23:194|-1948.

16. Jones PH, Watt FM: Separation of human epidermal stem cells from transit amplifying cells on the basis of differences in integrin function and expression. Cell 1993, 73:713-724.

17. Li A, Simmons PJ, Kaur P: Identification and isolation of candidate human keratinocyte stem cells based on cell surface phenotype. Proc Natl Acad Sci USA 1998, 95:3902-3907.

18. Pajoohesh-Ganji A, Pal-Ghosh S, Simmens SJ, Stepp MA: Integrins in slow-cycling corneal epithelial cells at the limbus in the mouse. Stem Cells 2006, 24:1075-1086.

19. Shinohara T, Avarbock MR, Brinster RL: betal- and alpha6integrin are surface markers on mouse spermatogonial stem cells. Proc Natl Acad Sci USA 1999, 96:5504-5509.

20. Suzuki $A$, Zheng $Y$, Kondo R, Kusakabe M, Takada $Y$, Fukao $K$, Nakauchi $H$, Taniguchi $H$ : Flow-cytometric separation and enrichment of hepatic progenitor cells in the developing mouse liver. Hepatology 2000, 32: 1230-1239.

21. Watt FM, Kubler MD, Hotchin NA, Nicholson LJ, Adams JC: Regulation of keratinocyte terminal differentiation by integrin extracellular matrix interactions. J Cell Sci 1993, I06(Pt I): $175-182$.
22. Heer R, Collins AT, Robson CN, Shenton BK, Leung HY: KGF suppresses alpha2betal integrin function and promotes differentiation of the transient amplifying population in human prostatic epithelium. J Cell Sci 2006, I I 9:|4|6-|424.

23. Flanagan LA, Rebaza LM, Derzic S, Schwartz PH, Monuki ES: Regulation of human neural precursor cells by laminin and integrins. J Neurosci Res 2006, 83:845-856.

24. Tarasenko YI, Yu Y, Jordan PM, Bottenstein J, Wu P: Effect of growth factors on proliferation and phenotypic differentiation of human fetal neural stem cells. J Neurosci Res 2004, 78:625-636.

25. Svendsen CN, ter Borg MG, Armstrong RJ, Rosser AE, Chandran S, Ostenfeld T, Caldwell MA: A new method for the rapid and long term growth of human neural precursor cells. J Neurosci Methods 1998, 85: |4I-I52.

26. Reynolds BA, Weiss S: Generation of neurons and astrocytes from isolated cells of the adult mammalian central nervous system. Science 1992, 255:1707-1710.

27. Svendsen CN, Fawcett JW, Bentlage C, Dunnett SB: Increased survival of rat EGF-generated CNS precursor cells using B27 supplemented medium. Exp Brain Res 1995, 102:407-414.

28. Miner JH, Yurchenco PD: Laminin functions in tissue morphogenesis. Annu Rev Cell Dev Biol 2004, 20:255-284.

29. van Engeland M, Nieland LJ, Ramaekers FC, Schutte B, Reutelingsperger CP: Annexin V-affinity assay: a review on an apoptosis detection system based on phosphatidylserine exposure. Cytometry 1998, $31:$ I-9.

30. Hall PE, Lathia JD, Miller NG, Caldwell MA, ffrench-Constant C: Integrins are markers of human neural stem cells. Stem Cells 2006, 24:2078-2084.

31. Dixit SN: Isolation, purification and characterization of intact and pepsin-derived fragments of laminin from human placenta. Connect Tissue Res 1985, I 4:31-40.

32. Wondimu Z, Gorfu G, Kawataki T, Smirnov S, Yurchenco P, Tryggvason K, Patarroyo M: Characterization of commercial laminin preparations from human placenta in comparison to recombinant laminins 2 (alpha2betalgammal), 8 (alpha4beta I gammal), 10 (alpha5beta I gammal). Matrix Biol 2006, 25:89-93.

33. Timpl R, Rohde H, Robey PG, Rennard SI, Foidart JM, Martin GR: Laminin-a glycoprotein from basement membranes. J Biol Chem 1979, 254:9933-9937.

34. Martin MJ, Muotri A, Gage F, Varki A: Human embryonic stem cells express an immunogenic nonhuman sialic acid. Nat Med 2005, 11:228-232.

35. Arroyo AG, Sanchez-Mateos P, Campanero MR, Martin-Padura I, Dejana E, Sanchez-Madrid F: Regulation of the VLA integrin-ligand interactions through the beta I subunit. J Cell Biol I992, I 1 7:659-670.

36. Giancotti FG, Tarone G: Positional control of cell fate through joint integrin/receptor protein kinase signaling. Annu Rev Cell Dev Biol 2003, 19:173-206.

37. Knight CG, Morton LF, Onley DJ, Peachey AR, Messent AJ, Smethurst PA, Tuckwell DS, Farndale RW, Barnes MJ: Identification in collagen type $I$ of an integrin alpha2 beta I-binding site containing an essential GER sequence. I Biol Chem 1998, 273:33287-33294.

38. Baron W, Shattil SJ, ffrench-Constant C: The oligodendrocyte precursor mitogen PDGF stimulates proliferation by activation of alpha(v)beta3 integrins. EMBO / 2002, 21:1957-1966.

39. Temple S: Division and differentiation of isolated CNS blast cells in microculture. Nature 1989, 340:47।-473.

40. Davis AA, Temple S: A self-renewing multipotential stem cell in embryonic rat cerebral cortex. Nature 1994, 372:263-266.

4I. Qian X, Davis AA, Goderie SK, Temple S: FGF2 concentration regulates the generation of neurons and glia from multipotent cortical stem cells. Neuron 1997, 18:8I-93.

42. Piao $\mathrm{JH}$, Odeberg J, Samuelsson EB, Kjaeldgaard A, Falci S, Seiger A Sundstrom E, Akesson E: Cellular composition of long-term human spinal cord- and forebrain-derived neurosphere cultures. I Neurosci Res 2006, 84:47I-482.

43. Sakaguchi M, Shingo T, Shimazaki T, Okano HJ, Shiwa M, Ishibashi S, Oguro $H$, Ninomiya M, Kadoya T, Horie H, Shibuya A, Mizusawa $H$, Poirier F, Nakauchi H, Sawamoto K, Okano H: A carbohydratebinding protein, Galectin- $I$, promotes proliferation of adult neural stem cells. Proc Natl Acad Sci USA 2006, 103:7 I I2-7 I I7. 
44. Taupin P, Ray J, Fischer WH, Suhr ST, Hakansson K, Grubb A, Gage FH: FGF-2-responsive neural stem cell proliferation requires CCg, a novel autocrine/paracrine cofactor. Neuron 2000, 28:385-397.

45. Selverstone VJ, Doucette PA, Zittin PS: Copper-zinc superoxide dismutase and amyotrophic lateral sclerosis. Annu Rev Biochem 2005, 74:563-593.

46. Michiels C, Raes M, Toussaint O, Remacle J: Importance of Se-glutathione peroxidase, catalase, and $\mathrm{Cu} / \mathrm{Zn}$-SOD for cell survival against oxidative stress. Free Radic Biol Med 1994, I 7:235-248.

47. Uchida N, Buck DW, He D, Reitsma MJ, Masek M, Phan TV, Tsukamoto AS, Gage FH, Weissman IL: Direct isolation of human central nervous system stem cells. Proc Natl Acad Sci USA 2000 97:|4720-14725.

48. Wright LS, Li J, Caldwell MA, Wallace K, Johnson JA, Svendsen CN: Gene expression in human neural stem cells: effects of leukemia inhibitory factor. J Neurochem 2003, 86: 179-195.

49. Molofsky AV, Pardal R, Morrison SJ: Diverse mechanisms regulate stem cell self-renewal. Curr Opin Cell Biol 2004, 16:700-707.

50. Leone DP, Relvas JB, Campos LS, Hemmi S, Brakebusch C, Fassler R, ffrench-Constant $C$, Suter U: Regulation of neural progenitor proliferation and survival by betal integrins. J Cell Sci 2005 , I I 8:2589-2599.

51. Blaschke AJ, Weiner JA, Chun J: Programmed cell death is a universal feature of embryonic and postnatal neuroproliferative regions throughout the central nervous system. J Comp Neurol 1998, 396:39-50.

52. Oppenheim RW: The neurotrophic theory and naturally occurring motoneuron death. Trends Neurosci 1989, I 2:252-255.

53. Kuida K, Zheng TS, Na S, Kuan C, Yang D, Karasuyama H, Rakic P, Flavell RA: Decreased apoptosis in the brain and premature lethality in CPP32-deficient mice. Nature 1996, 384:368-372.

54. Kuida K, Haydar TF, Kuan CY, Gu Y, Taya C, Karasuyama H, Su MS, Rakic P, Flavell RA: Reduced apoptosis and cytochrome c-mediated caspase activation in mice lacking caspase 9. Cell 1998, 94:325-337.

55. Honarpour N, Du C, Richardson JA, Hammer RE, Wang X, Herz J: Adult Apaf-I-deficient mice exhibit male infertility. Dev Biol 2000, 21 8:248-258.

56. Yeo W, Gautier J: Early neural cell death: dying to become neurons. Dev Biol 2004, 274:233-244.

57. de la Rosa EJ, de Pablo F: Cell death in early neural development: beyond the neurotrophic theory. Trends Neurosci 2000 23:454-458.

58. Fish JL, Kosodo Y, Enard W, Paabo S, Huttner WB: Aspm specifically maintains symmetric proliferative divisions of neuroepithelial cells. Proc Natl Acad Sci USA 2006, 103: 10438 - 10443.

59. Thibert C, Teillet MA, Lapointe F, Mazelin L, Le Douarin NM, Mehlen $P$ : Inhibition of neuroepithelial patched-induced apoptosis by sonic hedgehog. Science 2003, 30 I:843-846.

60. Chi H, Sarkisian MR, Rakic P, Flavell RA: Loss of mitogen-activated protein kinase kinase kinase 4 (MEKK4) results in enhanced apoptosis and defective neural tube development. Proc Natl Acad Sci USA 2005, I02:3846-385I.

61. McFarland KN, Wilkes SR, Koss SE, Ravichandran KS, Mandell JW: Neural-specific inactivation of ShcA results in increased embryonic neural progenitor apoptosis and microencephaly. J Neurosci 2006, 26:7885-7897.

62. Sabapathy K, Jochum W, Hochedlinger K, Chang L, Karin M, Wagner EF: Defective neural tube morphogenesis and altered apoptosis in the absence of both JNKI and JNK2. Mech Dev 1999, 89: $115-124$

63. Kuan CY, Yang DD, Samanta Roy DR, Davis RJ, Rakic P, Flavell RA: The JnkI and Jnk2 protein kinases are required for regional specific apoptosis during early brain development. Neuron 1999, 22:667-676.

64. Sinor AD, Lillien L: Akt-I expression level regulates CNS precursors. J Neurosci 2004, 24:853I-854I.

65. Caldwell MA, He X, Wilkie N, Pollack S, Marshall G, Wafford KA Svendsen CN: Growth factors regulate the survival and fate of cells derived from human neurospheres. Nat Biotechnol 200I, 19:475-479.

66. Miyamoto S, Akiyama SK, Yamada KM: Synergistic roles for receptor occupancy and aggregation in integrin transmembrane function. Science 1995, 267:883-885.
67. Yoneda A, Couchman JR: Regulation of cytoskeletal organization by syndecan transmembrane proteoglycans. Matrix Biol 2003, 22:25-33.

68. Moore SA, Saito F, Chen J, Michele DE, Henry MD, Messing A, Cohn RD, Ross-Barta SE, Westra S, Williamson RA, Hoshi T, Campbell KP: Deletion of brain dystroglycan recapitulates aspects of congenital muscular dystrophy. Nature 2002, 4I 8:422-425.

69. Michele DE, Barresi R, Kanagawa M, Saito F, Cohn RD, Satz JS, Dollar J, Nishino I, Kelley RI, Somer H, Straub V, Mathews KD, Moore SA, Campbell KP: Post-translational disruption of dystroglycan-ligand interactions in congenital muscular dystrophies. Nature 2002, 41 8:417-422

70. Nagato M, Heike T, Kato T, Yamanaka Y, Yoshimoto M, Shimazaki T, Okano H, Nakahata T: Prospective characterization of neural stem cells by flow cytometry analysis using a combination of surface markers. J Neurosci Res 2005, 80:456-466.

7I. Woods A, Couchman JR, Johansson S, Hook M: Adhesion and cytoskeletal organisation of fibroblasts in response to fibronectin fragments. $E M B O \mathrm{~J}$ 1986, 5:665-670.

72. Bull ND, Bartlett PF: The adult mouse hippocampal progenitor is neurogenic but not a stem cell. J Neurosci 2005, 25: $108|5-1082|$.

73. Seaberg RM, van der KD: Adult rodent neurogenic regions: the ventricular subependyma contains neural stem cells, but the dentate gyrus contains restricted progenitors. J Neurosci 2002, 22: 1784- 7793.

74. Doetsch F, Petreanu L, Caille I, Garcia-Verdugo JM, Alvarez-Buylla A: EGF converts transit-amplifying neurogenic precursors in the adult brain into multipotent stem cells. Neuron 2002, 36:1021-1034.

75. Doetsch F, Verdugo JM, Caille I, Alvarez-Buylla A, Chao MV, CasacciaBonnefil P: Lack of the cell-cycle inhibitor p27Kip I results in selective increase of transit-amplifying cells for adult neurogenesis. J Neurosci 2002, 22:2255-2264.

76. Reynolds BA, Rietze RL: Neural stem cells and neurospheresre-evaluating the relationship. Nat Methods 2005, 2:333-336.

77. Wu P, Tarasenko YI, Gu Y, Huang LY, Coggeshall RE, Yu Y: Regionspecific generation of cholinergic neurons from fetal human neural stem cells grafted in adult rat. Nat Neurosci 2002, 5:127I-I278.

78. Soen Y, Mori A, Palmer TD, Brown PO: Exploring the regulation of human neural precursor cell differentiation using arrays of signaling microenvironments. Mol Syst Biol 2006, 2:37.

79. Goetz AK, Scheffler B, Chen HX, Wang S, Suslov O, Xiang H, Brustle $O$, Roper SN, Steindler DA: Temporally restricted substrate interactions direct fate and specification of neural precursors derived from embryonic stem cells. Proc Natl Acad Sci USA 2006, I03: I 1063-II068.
Publish with Bio Med Central and every scientist can read your work free of charge

"BioMed Central will be the most significant development for disseminating the results of biomedical research in our lifetime. "

Sir Paul Nurse, Cancer Research UK

Your research papers will be:

- available free of charge to the entire biomedical community

- peer reviewed and published immediately upon acceptance

- cited in PubMed and archived on PubMed Central

- yours - you keep the copyright
BioMedcentral 